\title{
LEISURE PRODUCTS
}

From art to

yachting, hundreds of sports

and leisure

activities are

available to

disabled people

today. The right

type of equipment

can make a

chosen pursuit

possible or more

enjoyable, as

Jenny Nissler

explains.

\section{USEFUL INFORMATION}

\author{
Disability Information \\ Trust \\ Mary Marlborough Centre \\ Nuffield Orthopaedic \\ Centre NHS Trust \\ Headington \\ Oxford OX3 7LD \\ Tel: 01865227592 \\ Publications include \\ 'Gardening', price $£ 5.00$, \\ post free
}

\section{RADAR}

12 City Forum

150 City Road

London EC1V 8AF

Tel: 01712503222
T here are currently more than 50,000 members of the British Sports Association for the Disabled, participating in over 500 sports clubs.

Others tend gardens, contribute to the arts, or enjoy a variety of sedentary activities, according to preference.

\section{WHICH ACTIVITY?}

Most activities are possible, and many disabled people achieve more than they, or their carers, expect! However, be realistic. Consider the extent of disability and ability. For general advice on taking up activities, and for a list of useful addresses, see 'Sport and hobbies', page 223.

\section{WHAT EQUIPMENT?}

This will depend upon the activity chosen, and on the aptitude, age and abilities of the individual.

In some cases, no special equipment is necessary. A blind skier will use the same equipment as other people.

Often, adaptations are made to standard equipment. Stabilisers might be affixed to the wheels of a wheelchair fencer, to give extra stability, for instance.

Specialised equipment may sometimes be needed, such as longhandled gardening tools (see the Disability Information Trust's 'Equipment for disabled people', books), or battery-operated playing card shufflers, for example.

Most clubs for disabled people will provide equipment wherever possible. Your local occupational therapy department may be able to suggest adaptations.

\section{ACCESS}

Very often, the only equipment needed is that which allows the disabled person access to their chosen activity.

Do they need wheelchair access? Is there a hoist to help with getting in and out of a swimming pool? Check before going. The Sports Council publishes a guide to sports centres with access for disabled people, in association with RADAR.

\section{CLOTHING}

Appropriate clothing and footwear should be worn - again, take advice on this. Your local occupational therapist may be able to give tips on adaptations.

\section{SPORTS BRACES/JOINT SUPPORTS}

Sometimes, a wrist splint or knee brace, for example, may provide extra support or stability, or prevent painful joints.

Your physiotherapist or doctor may be able to help. Some braces and supports may be provided by the NHS. Other sources are local sports shops, although the quality of product may vary.

\section{PAIN RELIEF}

Disabled people are subject to the same aches and pains as everyone else! For severe or persistent pain, it is important to see the doctor, but for muscle aches or strain after activity, hot packs or cold compresses may help.

Reusable versions of such packs are available at some chemists, but check with the physiotherapist before buying. 